Revista de Estudios Histórico-Jurídicos [Sección historia del pensamiento jurídico]

XLII (Valparaíso, Chile, 2020)

[pp. 721-733]

\title{
DEL ESTADO AL ALMA: REFLEXIONES EN TORNO A LA JUSTICIA SOCIAL E INDIVIDUAL EN EL LIBRO IV DE La REPÚbLICA DE Platón
}

[From state to soul: thoughts on social and individual justice of Book IV in Plato's The Republic]

\author{
Marcelo Espinosa Aguilar* \\ Pontificia Universidad Católica de Valparaíso, Chile
}

\section{RESUMEN}

El propósito de este trabajo es examinar la concepción platónica de la justicia expuesta en el Libro IV de La República. En miras a este cometido, iniciaremos con algunas consideraciones generales sobre la obra y justificaremos la opción por este Libro en particular. Atendida la doble perspectiva desde la que el autor aborda la justicia, nos haremos cargo, separadamente, de su vertiente social (radicada en la $\pi 0 ́ \lambda ı \varsigma)$ e individual (propia de la $\psi v \chi \eta$ ). En ambos casos, haremos especial hincapié en la particular estrategia metodológica utilizada por el autor, consistente en la tripartición de la polis y el alma. Sobre este punto, propondremos, por una parte, una relectura de la relación entre las dos clases de justicia y, por otra, matizaremos el subrayado carácter interno de la justicia individual. Finalmente, y ya caracterizada por completo la justicia, concentraremos nuestras reflexiones en el rol que ocupa la ley.

Palabras clave

Platón - La República - justicia - polis - alma - ley.

\section{Abstract}

The aim of this paper is to review the conception of justice of Book IV in Plato's The Republic. We will start with some general considerations about the work that justify the choice for this particular Book. Justice is approached by the author from a double perspective. We will develop an understanding separately, of its social (based on the $\pi$ ó $\lambda$ เ ) and individual (own of the $\psi v \chi \eta$ ). In both cases, we will place special emphasis on the particular methodological strategy used by the author, consisting on the tripartition of the polis and the soul. On this point, we will propose a rereading of the relationship between the two kinds of justice and we will clarify the underlined internal character of individual justice. Finally, and once justice is fully characterized, we will concentrate our reflections on the role of the law on the platonic state.

\section{KEY WordS \\ Plato - The Republic - justice - polis - soul - law.}

RECIBIDO el 17 de octubre de 2019 y ACEPTADO el 19 de junio de 2020

* Profesor agregado de Teoría y Filosofía del Derecho, Pontificia Universidad Católica de Valparaíso. Becario CONICYT-PFCHA/MagísterNacional/2019-22190379. Email: marcelo. espinosa@pucv.cl. El autor agradece las observaciones realizadas por el profesor Álvaro Pizarro Herrmann a una versión preliminar de este trabajo. 


\section{CONSIDERACIONES PRELIMINARES}

Sin lugar a dudas, La República (cuyo verdadero nombre es $\pi 0 \lambda \iota \tau \varepsilon i ́ \alpha$ ) constituye una de las más importantes obras del corpus platónico. En ella, a través de su característico diálogo como forma literaria, son abordadas temáticas tales como la educación, formas de gobierno, las virtudes y la concepción del alma; todo esto, por cierto, en el marco de su conocida teoría de las ideas. Con todo, y sin perjuicio de las diversas reflexiones contenidas, el eje central de la obra estriba en desentrañar la naturaleza de la justicia e injusticia y sus respectivas consecuencias para el hombre justo e injusto ${ }^{2}$. No en vano, por idéntica razón, Trasilo le agregó como segundo título "acerca de la justicia", pues, primordial o tangencialmente, es el tema que irradia cada uno de los diez libros que componen la obra.

Para Platón, la justicia ocupa un privilegiado rol dentro del esquema general de virtudes y se caracteriza por poseer una doble faz: primero, una de carácter s o c i a 1 , propia de la polis ( $\pi$ ó $\lambda ı \varsigma)$; y, luego, una dimensión i n d i v i d u a l, cuya sede es el alma ( $\psi v \chi \eta ́)$. Una y otra, como veremos, no pueden ser entendidas de manera absolutamente independiente. Lo que existe, más bien, es una relación de interdependencia. De esta forma, el tratamiento platónico de la justicia no hace sino confirmar su ya conocida tesis acerca de la importancia del aspecto comunitario en el desarrollo de una buena vida ${ }^{3}$ en aras a la consecución de la idea de Bien. En este sentido, la idea de justicia deriva su valor precisamente de la idea de Bien, razón que explicaría por qué Platón, en algunos pasajes, llega incluso a identificarlas ${ }^{4}$.

Pues bien, atendido el protagonismo de la justicia en La República, acotaremos nuestro análisis al Libro IV de la mencionada obra; la elección no es, en ningún caso, obra de un capricho: se trata, indudablemente, de la sección con las más sistemáticas dilucidaciones sobre el tema y que proporciona suficientes elementos para una adecuada aproximación a la problemática.

Antes de iniciar nuestras reflexiones, es menester efectuar una aclaración, tal vez obvia, pero necesaria: el análisis de una teoría de la justicia como la platónica, exige al lector despojarse previamente de las actuales concepciones de justicia por el sencillo hecho de que La República data del siglo IV a.C y, como es evidente, las circunstancias políticas, sociales y culturales distan bastante de la realidad

${ }^{1}$ Para la presente investigación nos valdremos de la traducción realizada por José Manuel Pabón y Manuel Fernández-Galiano, publicada por Alianza Editorial. En lo sucesivo, las citas a esta obra irán entre paréntesis.

${ }^{2}$ Guthrie, W.K.C, Historia de la filosofía griega, IV: Platón. El hombre y sus diálogos: primera época (Madrid, Gredos, 1998), p. 416.

${ }^{3}$ Ibíd, p. 417.

${ }^{4}$ Kelsen, Hans, Platonic justice, en Ethics, 48/3 (1938), p. 390. Anticipando, desde ya, algunas ideas que expondremos, Kelsen puntualiza correctamente: "Como el bien es una categoría estrictamente social, se deduce que solo en el Estado el hombre puede actuar de conformidad con el bien; en efecto, es solo en el Estado en que el hombre como su órgano puede conocer el bien. [...] Por lo tanto, el punto central de La República está en la explicación del problema del bien; y es por esta razón que la culminación de este trabajo sobre el Estado es la teoría de las ideas, la más alta de las cuales parece ser la idea del bien”. La traducción es nuestra. 
actual. La pregunta por la justicia ha recibido innumerables respuestas desde las más diversas veredas teóricas: es de aquellas interrogantes para las que, siguiendo a Kelsen, jamás tendremos respuesta definitiva sino solo podemos procurar preguntar mejor ${ }^{5}$. En cualquier caso, criticar el cometido del autor a la luz de las circunstancias y teorías de la justicia actuales sería anacrónico ${ }^{6}$. Nuestro análisis iniciará con la dimensión social de la justicia.

\section{EL UNITARISMO PLATÓNICO Y LA JUSTICIA EN LA POLIS}

Ante todo, Platón contempla a la polis no como una compleja amalgama de elementos individuales: esta es, en sí misma, la gran unidad ${ }^{7}$. De esta forma, bajo el alero de este unitarismo subyacente ${ }^{8}$, arribamos a una consecuencia estructural: la polis debe ser establecida en miras al mayor grado de felicidad posible para la ciudad toda y no a la de un específico grupo (420b), toda vez que -valiéndose de una ilustrativa metáfora-, al igual que en una escultura, para hacer hermoso al conjunto es pertinente darle a cada parte lo que es propio (420d). Corresponderá, consecuentemente, optar por la prosperidad de la polis en su conjunto ya que solo así se procurará que cada clase integrante de esta tome su respectiva parte de felicidad (421c). El éxito de esta empresa dependerá, sin embargo, de la concurrencia de ciertas condiciones y será el propio autor quien nos va a proporcionar los cimientos sobre los cuales se esgrime una ciudad buena y, por consiguiente, "prudente, valerosa, moderada y justa" (427e).

La propuesta metodológica del autor se estatuye a partir de un fundamental concepto: la fu n c ión es p e cífic a (también llamado p ri n c i p i o d e e s p e c i a l i z a c i ó n ). Este principio, a juicio de Platón, implica someter a los ciudadanos que componen la polis a una estructuración piramidal, distinguiéndose claramente tres grupos: en la cúspide, encontramos a la clase gobernante, cuya función es la de dirección política; luego, están los guerreros, encargados de proteger o salvaguardar la ciudad; por último, están los obreros y artesanos, cuyo papel es proveer de servicios y alimento, según sea requerido. Trazar esta distinción, como es evidente, significa conferir una significativa jerarquización a la sociedad ${ }^{9}$, pero Platón avanza un paso más y, junto con conferirle una específica función a cada escalafón, le atribuye una virtud preponderante. Así, la virtud propia de la clase

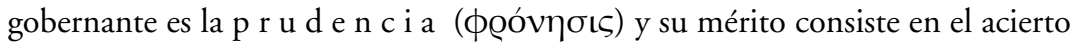

${ }^{5}$ Kelsen, Hans, ¿Qué es la justicia? (México D.F, Fontamara, 1991), p. 8.

${ }^{6}$ De esta forma, y aunque parezca contraproducente, sería un error suponer que la igualdad es una noción inherente a toda concepción de la justicia. La justicia ha sido, con toda seguridad, un propósito gubernamental desde la época griega; lo reciente, en cambio, es la creencia de que la justicia requiere igualdad. Vid. Foster, M.B., On Plato's conception of justice in the Republic, en The Philosophical Quarterly (1951), 3, pp. 209-210.

${ }^{7}$ Graneris, Giuseppe, El concepto de justicia en Sócrates, Platón y Aristóteles, en Revista de Derecho Público, 17 (2014), p. 13.

${ }^{8}$ Esta idea estaría presente, asimismo, en un pasaje de la obra en que Platón arguye que el único límite al crecimiento de la polis es que siga siendo u n a (423b).

${ }^{9}$ CaÑas Quirós, Roberto, La justicia en el alma del filósofo según Platón, en Revista de Filosofía de la Universidad de Costa Rica, 81 (1995), p. 199. 
de las determinaciones de la polis (428b), guiando a los gobernados por el camino que dicte la recta razón. La clase guerrera, por su parte, se caracteriza por ser la

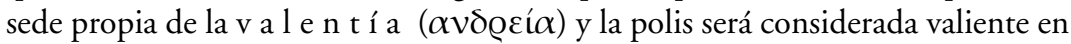
exclusiva consideración a este grupo encargado de la defensa (429a-b). A la última clase le corresponde, finalmente, la t e m p l a n z a ( $\sigma \omega \phi \emptyset o \sigma u ́ v \eta)$, la que, de un modo musical o armonioso, permite hacer predominar lo mejor por sobre lo peor (431a). Con todo, a pesar de que esta facultad de autogobierno sea propia de esta última clase, Platón enfatiza que no constituye un atributo exclusivo de un grupo, sino que se trata de una virtud transversal y común a gobernantes y gobernados $(431 e)^{10}$. Una vez clarificado el panorama general de las virtudes, subsiste, empero, la pregunta por la justicia. La respuesta a esta legítima interrogante es introducida de magnífica manera por los interlocutores del diálogo, puntualizando que detrás de toda la precedente exposición estuvo siempre presente la justicia, habiendo sido ridículamente desapercibida por ellos (432d-e). Hagamos patente su reconocida desprolijidad, explicitando el quid del asunto.

A pesar de no ser conceptos absolutamente idénticos ${ }^{11}$, el principio de especialización coadyuva sustancialmente a la consecución de la justicia social. En consecuencia, el reconocimiento y categorización de las diferentes clases, funciones y virtudes preponderantes nos permite colegir que cada cual deberá cumplir un específico cometido, pero no cualquiera, sino aquél para el que su naturaleza esté mejor dotada $(433 a)^{12}$. Consecuentemente, la justicia, en su dimensión social, consiste en "hacer cada uno lo suyo"13 (433b) y, en ningún caso, multiplicar sus actividades más allá de las que le correspondan ${ }^{14}$. Entendida así, la justicia constituye, por tanto, una virtud universal ${ }^{15}$, pues se trata del corolario de la armónica e íntegra verificación de las tres virtudes previamente analizadas; pero no solo eso, además de ser consecuencia, es, asimismo, causa de su adecuada presencia. En

${ }^{10}$ En otro pasaje de La República se afirma que "así como el valor y la prudencia, residiendo en una parte de la ciudad, la hacen a toda ella el uno valerosa y la otra prudente, la templanza no obra igual, sino que s e e t i e n d e p o r la ci u d a d e n t e r a, logrando que canten lo mismo y en perfecto unísono los más débiles, los más fuertes y los de en medio, ya los clasifiques por su inteligencia, ya por su fuerza, ya por su número o riqueza o por cualquier otro semejante respecto; de suerte que podríamos con razón afirmar que es templanza esta concordia, esta armonía entre lo que es inferior y lo que es superior por naturaleza sobre cuál de esos dos elementos debe gobernar ya en la ciudad, ya en cada individuo" (431e-432a). El espaciado es nuestro.

${ }^{11}$ Annas, Julia, An introduction to Plato's Republic (New York, Oxford University Press, 1981), p. 119.

${ }^{12}$ Vinculando los conceptos de unidad, especialización y justicia, Annas recalca que la justicia es una virtud de la ciudad como unidad, toda vez que requiere que cada ciudadano reconozca su propio papel en la contribución, de alguna manera característica, al bien común. Ibíd.

${ }^{13}$ Y no "d a r a cada uno lo suyo", como reza la formulación del jurista romano Ulpiano (suum cuique tribuere). La diferencia, aunque parezca mínima, revela diferencias sustanciales.

${ }^{14}$ Refuerza este punto al señalar que "lo que mayormente hace buena a la ciudad es que se asiente en el niño y en la mujer y en el esclavo y en el hombre libre y en el artesano y en el gobernante y en el gobernado eso otro de que cada uno haga lo suyo y n o s e d e d i q u e a m á s” (433d). El espaciado es nuestro.

${ }^{15}$ Graneris, Giuseppe, cit. (n. 7), p. 14 
efecto, la justicia le da a la templanza, valor y prudencia el vigor necesario para su nacimiento y, después de nacidas, las conserva mientras subsiste en ellas (433b-c).

Así las cosas, la justicia se vería afectada en la medida que existan ciudadanos que no realizaren aquello que les es propio ${ }^{16}$. Esta idea, empero, merece ser estudiada con un mayor detenimiento. En efecto, y guiado nuevamente por su unitarismo, Platón desplaza a un segundo plano aquellas interferencias existentes entre una misma clase social, pues las verdaderamente preocupantes y auténticamente calificadas como injusticias son solo aquellas derivadas del entrometimiento de una clase a otra, atendidas las perniciosas consecuencias que estas podrían ocasionar a la polis en su totalidad (434a-c) ${ }^{17}$. En definitiva, y como ha destacado Popper, se evidencia un cariz profundamente holista y antiigualitario ${ }^{18}$ en la teoría platónica de la justicia.

Finalmente, y ya habiendo perfilado el esquema platónico en esta sede, un último aspecto a dilucidar es de qué modo se imparte la justicia en la $\pi o ́ \lambda ı \varsigma$ o, en otros términos, de qué manera es posible garantizar el unitarismo y el principio de especialización ya aludidos. Sobre el particular, no es ninguna novedad afirmar que el modelo propugnado por el autor solo puede ser alcanzado en un Estado de tinte autoritario. Junto con admitir la inexorable desigualdad entre personas y clases sociales, Platón no reconoce ningún derecho a las personas, sino únicamente deberes éticos y sociales ${ }^{19}$, postulados que no hacen sino negar los principios que impregnan todo ideal democrático. Pues bien, en el sistema descrito por el autor, las autoridades públicas son quienes deben calificar las aptitudes de cada individuo y, por ende, situarlo en el lugar que sea más adecuado (415a-b). Así pues, desde esta perspectiva, la justicia no se administra -como se afirma comúnmente en la actualidad-por medio de un complejo cuerpo de reglas de general aplicación

${ }^{16}$ En directo detrimento de la justicia irían, a juicio de Platón, la riqueza y la indigencia: "la una trae la molicie, la ociosidad y el prurito de novedades, y la otra, este mismo prurito y, a más, la vileza y el mal obrar" (422a).

${ }^{17}$ Esta idea se ve ilustrada en el diálogo, al señalar que si el carpintero realiza el trabajo del zapatero y viceversa o que uno intente asumir ambas funciones, "no parece afectar gravemente la ciudad”, como sí ocurriría, en cambio si un artesano entrara en la clase de los guerreros o uno de los guerreros en la de los gobernantes, sin tener mérito para ello. Esta última situación descrita sería "ruinosa para la ciudad" (434a-b).

${ }^{18}$ En relación a este punto, Popper subraya el novedoso carácter antiigualitario de la justicia en La República, contrario a lo que el mismo Platón planteara previamente en el diálogo Gorgias, así como también al tratamiento que posteriormente hiciera Aristóteles. De esta forma, existiría una declarada renuncia a la igualdad como núcleo de la justicia, definiéndola precisamente del modo opuesto, esto es, como d e s i g u a $1 \mathrm{~d}$ a d . Las razones que esboza Popper para explicar este giro conceptual están fundadas, a su juicio, en la necesidad de Platón por hacer propaganda a su Estado totalitario, intentando convencer a la gente de que se trataba de un Estado j u $s$ t o . Lo importante, a juicio de Popper, no son las palabras empleadas sino sus significaciones; pero en este caso, la extendida popularidad del término y la lucha por su consecución, habría logrado persuadir a los lectores no solo de su época sino también hasta nuestros días. POPPER, Karl, $L a$ sociedad abierta y sus enemigos (Barcelona, Paidós, 2006), pp. 106-108.

${ }^{19}$ Bodenheimer, Edgar, Teoría del Derecho (México D.F, Fondo de Cultura Económica, 1994), p. 66. 
que podemos denominar derecho; antes bien, para Platón, la justicia se realiza mediante el ejercicio del poder ${ }^{20}$.

Luego de la caracterización de la justicia social, el diálogo posterior del Libro IV traslada sus disquisiciones a un escenario -aparentemente- distinto, pues se transita desde la polis al alma, desarrollando así su teoría de la justicia en esta nueva sede. Cabe recalcar, sin embargo, que el tratamiento primario de la justicia social no es una cuestión baladí: se trata del principio a r qu i t e c t ó n i c o de los dos tipos de justicia que, como veremos, se erige como condición de posibilidad del equilibrio interno del individuo ${ }^{21} \mathrm{y}$, en consecuencia, de la segunda clase de justicia a analizar.

\section{El ALMA COMO UNA PEQUEÑA POLIS}

Del mismo modo efectuado precedentemente, Platón sostiene que el alma admite una idéntica escisión tripartita; la hipótesis, consiste, por tanto, en trasladar y replicar la estrategia metodológica de la $\pi o ́ \lambda ı \varsigma$ hacia la $\psi v \chi \eta ́ ~(434 d)$. Como señala Guthrie, toda persona posee en alguna medida todas las características psicológicas; lo importante será, entonces, determinar cuál es la dominante ${ }^{22}$. Así, el autor señala que es posible distinguir, al interior de la polis, una parte racional (tó logistikon tês psychés), cuya virtud propia es la phronesis; una parte volitiva o irascible ( $\theta u \mu o ́ \varsigma)$, que debe estar dominada por la andreia; y una parte sensitiva o

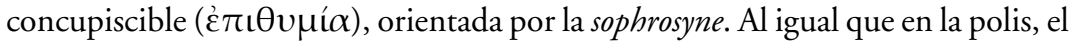
gobierno del alma corresponde a la parte racional, que deberá ser capaz de dominar los impulsos provenientes de parte concupiscible y recibiendo siempre la ayuda de la parte irascible para tal cometido. En este esquema, "el hombre justo no diferirá en nada de la ciudad justa en lo que se refiere a la idea de justicia” (435b), por lo que el alma será justa siempre y cuando exista una recta armonía entre las tres partes que la componen ${ }^{23}$. En efecto, la justicia puede ser entendida, en esta sede, como la condición interna y psicológica de una persona en la que cada una de estas tres partes ocupa aquel rol para el cual es naturalmente adecuado ${ }^{24}$ y siempre bajo el imperio de la razón ${ }^{25}$. Pero este parangón, como es evidente, se puede extender

\footnotetext{
${ }^{20}$ Ibid, p. 68.

${ }^{21}$ MoHr, Richard D., The eminence of social justice in Plato, en Illinois Classical Studies, 16/1-2 (1991), pp. 193-195.

${ }^{22}$ Guthrie, W.K.C, cit. (n. 2), p. 453.

${ }^{23}$ Sintetizando el gobierno de la razón en el alma, Cooper señala: "La razón, por sí sola y sin interferencia de los demás, determina cómo es mejor que la persona sea y actúe; la aspiración se identifica con las directivas de la razón, considerándolas como objetos por los que luchar y haciendo que la persona esté insatisfecha consigo misma si por su propia culpa no se logran; y el apetito, controlado y moderado por la razón y la aspiración, lo conduce hacia los placeres de comer, beber, sexuales y otras gratificaciones corporales cuando y como, y solo cuando y como, la razón lo aprueba". COOPER, John M., The psychology of justice in Plato, en American Philosophical Quarterly 14 (1977), 2, p. 151. La traducción es nuestra.

${ }^{24}$ Ibíd.

${ }^{25} \mathrm{Al}$ respecto, Gómez Robledo destaca el mérito de la contribución platónica, señalando que: "la tripartición del alma es uno de los hallazgos más geniales de Platón, y es algo, además, que se mantiene vivo hasta hoy, por lo menos en la filosofía escolástica [...]. [Platón] fue el
} 
igualmente a la injusticia, entendida ahora como toda desarticulación o desajuste entre los componentes del alma. Mutatis mutandis, en el alma de cada uno "hay las mismas clases que en la ciudad y en el mismo número" (441c).

Ahora bien, la explicación recién efectuada ha hecho que gran parte de los comentaristas de la obra platónica hagan especial hincapié en el carácter interno de la justicia individual, esto es, subrayando su consideración como la adecuada configuración interna del alma. Puestas así las cosas, una persona sería calificada como justa solo en la medida que los componentes de aquélla cumplan adecuadamente la función que por su naturaleza les corresponde, dejando de lado un relevante rasgo en concepciones posteriores (paradigmáticamente Aristóteles), como es la alteridad. En este sentido, Sachs ha dicho que, para Platón, en lo concerniente a la justicia, las reglas de conducta no constituyen nada esencial, pues esta es modelada no en términos de conducta y relaciones de personas, sino en términos de relación de partes del alma ${ }^{26}$. Empero, una lectura como la anterior adolece de una radical simplificación de la argumentación platónica; en efecto, si bien es correcto enfatizar el esencial carácter interno de la justicia individual (443d), concebirla solo de esta manera implicaría omitir arbitrariamente un aspecto accesorio pero no menos importante: la justicia reclama una manifestación conductual -por tanto, externa-y la cualificación de un comportamiento como tal vendrá dado precisamente por su aptitud (o no) de conservación y corroboración del armonioso estado interno del sujeto (443e $)^{27}$. En suma, la consideración de la justicia en la $\psi v \chi \eta ́$ no es puramente introspectiva pues requiere una exteriorización que la ratifique y consolide. En otras palabras, la justicia del alma es concebida, también, en términos deontológicos y no puramente ontológicos. La justicia individual, por tanto, debe ser concebida $\mathrm{p} \mathrm{r}$ i m o r d i a $1 \mathrm{~m}$ e $\mathrm{n}$ t e a la luz de la $\psi v \chi \eta$, pero no de modo exclusivo, ya que derivativamente irradia a las acciones $^{28}$. Mas con esto no se agotan nuestras reflexiones. Persiste, pendiente de análisis, un tema ya deslizado previamente pero sin su debida fundamentación: la relación entre la justicia social e individual.

Como hemos advertido, la estrategia utilizada por Platón al abordar la justicia

primero en constituirla en una psicología propiamente tal, al escrutar con todo rigor científico y con admirable agudeza de observación, nuestra vida interior. En nuestra opinión, no vemos hasta hoy de qué otro modo, fuera de la consabida tripartición funcional, pueda explicarse el combate íntimo que constituye literalmente nuestra vida cotidiana; este 'aprobar lo mejor y seguir lo peor"”. Gómez Robledo, Antonio, Platón. Los seis grandes temas de su filosofía (México D.F, Fondo de Cultura Económica, 1986), pp. 561-562.

${ }^{26}$ SaChs, David, A Fallacy in Plato's Republic, en The Philosophical Review, 72/2 (1963), pp. 157-158.

27 " [...] y después de enlazar todo esto y conseguir de esta variedad su propia unidad, entonces es cuando, bien templado y acordado, se pone a actuar así dispuesto ya en la adquisición de riquezas, ya en el cuidado de su cuerpo, ya en la política, ya en lo que toca a sus contratos privados, yen todo esto lojuzgay $\mathrm{d}$ e $\mathrm{n}$ o m i n a justa y bue n a a la a c c íón que conserve y corrobore ese estad o yprudencia al conocimiento que la presidayacción injusta, en cambio a la que destruya esta d i s p o s i c i ó n d e c o s a s [...]" (443e-444a). El espaciado es nuestro.

${ }^{28}$ Dahl, Norman O., Plato's defense of justice, en Philosophy and Phenomenological Research, 51/4 (1991), p. 812. 
puede ser sintetizada, según cómo se mire, en que la polis es una gran alma o el alma una pequeña polis. Con todo, a pesar de valerse de un aparataje conceptual similar en una y otra sede, podemos colegir que existe, en cierto sentido, una preeminencia de la justicia social que la situaría por sobre la individual. Una afirmación como la anterior, como es natural, requiere ser debidamente precisada. En efecto, la tesis recién propuesta no pretende, en ningún caso, propugnar una primacía formal de la justicia social; esto, por el sencillo hecho de que, en estricto rigor, se trata de lo mismo, pero aplicado a diferentes objetos $(443 \mathrm{~b})^{29}$. Antes bien, lo que queremos destacar es que el equilibrio interno del individuo (i.e., justicia en su sentido individual) solo es posible en una polis debidamente configurada (justa, en su sentido social), porque es esta última la que proporciona las condiciones necesarias para que las partes del alma puedan cumplir con sus respectivas funciones $^{30}$. El íntegro desarrollo del alma, entonces, está de cierto modo supeditado a la adecuada diversificación funcional de la polis, que determina en gran medida el éxito de dicho cometido. Lo anterior no significa en modo alguno desconocer la interdependencia antes destacada entre ambas clases de justicia: qué duda cabe que la recta conformación de las partes del alma de los individuos incide en la justicia de una polis. El punto que queremos destacar es que no existe una igual dependencia entre una y otra. Parece ser, por lo ya explicado, que el grado de incidencia que ejerce la polis en el individuo es superior al que este ejerce en aquella. Por lo tanto, y sin restarle vigor a la justicia individual, adquiere un sentido preciso la expresión utilizada más arriba, que erigía a la justicia en la polis como el p r i n c i p i o a r qu i t e c t ó n i c o de la justicia del alma: sería ésta, y no aquélla, la auténtica justicia primaria.

No obstante todo lo anteriormente explicado, un conocedor de la obra platónica podría, con justa razón, acusarnos de omitir un importante aspecto explicitado en el Libro en comento. Se trata, pues, de la discusión acerca del rol que ocupa

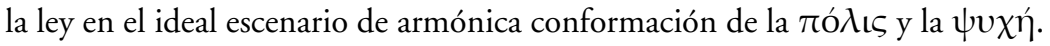

\section{III. ¿Y QUÉ QUEDA PARA LA LEY?}

El rechazo de Platón a la ley en La República goza de gran fama y aquí no haremos sino confirmar esa extendida y acertada observación. Lo que nos compete, por tanto, es desentrañar las razones de la irrestricta futilidad atribuida por el autor a un instrumento normativo de tanta relevancia en la actualidad. Así, en términos generales, la tesis platónica puede resumirse en que la ley es siempre

${ }^{29}$ En esta línea, Alcoberro Pericay destaca la importancia del alma, señalando que "es el vínculo que nos liga con las Ideas y nos permite aspirar al conocimiento. Y de la misma forma que condiciona nuestra manera de ser y de enfrentarnos al mundo, también determina la función política de cada individuo en la ciudad justa”. Alcoberro Pericay, Ramón, Platón. Las respuestas más vigentes a las grandes preguntas sobre el conocimiento, la ética o la justicia (Barcelona, RBA, 2015), p. 87. Considerable yerro sería, por tanto, restarle mérito a la $\psi v \chi \eta ́$ y a la justicia radicada en ella.

${ }^{30}$ Mohr, Richard D., cit. (n. 21), p. 196. 
inútil, pues si la república es sana, es superflua, y si está enferma, es ineficaz ${ }^{31}$. Con todo, una postura tan radical como la expuesta, requiere previamente dar cuenta de una serie de disquisiciones que llevan al autor a esa forzosa conclusión. Para ello, tendremos que volver sobre consideraciones generales de las categorías ya estudiadas, además de detenernos en algunas referencias explícitas del Libro IV sobre el particular.

La primera cuestión que debemos considerar es la ya explicada finalidad de La República. En efecto, esta obra constituye un verdadero manual de pedagogía política cuyo núcleo argumental estriba en la justicia y, por consiguiente, la ley-al igual que cualquier otra temática tratada en la obra- debe ser analizada a la luz de aquella. Pero si esta obra versa sobre la justicia, ¿por qué ha de desestimarse la ley si esta, prima facie, debe estar orientada por la justicia? La respuesta a esta inquietud se puede construir a partir de las nociones ya estudiadas, pues, como ya tuvimos la oportunidad de analizar, la justicia es entendida por Platón en un sentido ético-político, y la concibe como el corolario de la armoniosa convivencia de las virtudes en la polis y en el alma. A partir de ello, la teoría platónica socava las bases de la tradicional díada justicia-ley y, en consecuencia, sería impropio emplear la justicia en un sentido estrictamente legal. Como bien destaca Graneris, a menudo tendemos a equiparar justicia y derecho; Platón, por su parte, distinguió cuidadosamente uno del otro: la justicia acapara el orden ético desde la unidad, la coherencia y la armonía tanto en el individuo como en la polis, y las virtudes morales no serían sino concreciones de la justicia. El derecho, en cambio, no forma parte de este noble reino. Así pues, para construir su mundo Platón requiere irremediablemente a la justicia, pero prescinde del derecho y lo rechaza $^{32}$. Empero, con lo recién puntualizado solo hemos conseguido disociar la justicia de la ley. Avancemos un paso más y dilucidemos la razón de la drástica hostilidad hacia la ley.

Según Platón, la justicia (sea en la Tó $\lambda ı \varsigma$ o en la $\psi v \chi \eta ́)$ jamás podrá alcanzarse por obra de un ordenamiento jurídico, que por definición es impuesto forzosamente a los ciudadanos. Por ello, frente al fracaso coactivo de la ley, esta debe ser sustituida por la e d u c a c i ó n ( $\pi \alpha \iota \delta \varepsilon i ́ \alpha)$, atendido su carácter amplio, más penetrante y mucho más suave ${ }^{33}$. Por esta razón, voces autorizadas en la materia han señalado que el Platón de La República no es un legislador, sino un educador y que, en este contexto, el Estado platónico representaría una gigantesca abstracción pedagógica dotada de las aptitudes necesarias para generar un marco ideal de educación de hombres justos ${ }^{34}$. La educación, en estos términos, se erige como la auténtica guía de la virtud, como aquello que da dirección a la vida (425b) y que, al modo de la medicina, forja un alma saludable $\mathrm{e}^{35}$; la ley, en cambio, es superflua ex ante y ex post: primero, porque carece de la aptitud para

${ }^{31}$ Graneris, Giuseppe, cit. (n. 7), p. 16.

32 Ibíd.

33 Ibíd.

${ }^{34}$ JaEger, Werner, Alabanza de la ley. Los origenes de la filosofía del derecho y los griegos (Madrid, Centro de Estudios Constitucionales, 1982), pp. 57-58.

${ }^{35}$ Sobre el particular, Platón atribuye especial énfasis a la enseñanza de la gimnasia y la 
cimentarla, y luego porque "no vale la pena dar ordenanzas a hombres sanos y honrados: ellos mismos hallarán fácilmente la mayor parte de aquello que habría de ponerse por ley" (425d-e). Si en la clásica polis griega la ley era la formadora de los ciudadanos, en La República de Platón ese lugar lo ocupa la educación, que sustituye a la ley ${ }^{36}$, trascendiendo a cualquier imposición externa y propiciando el desarrollo y consolidación de personas justas.

Antes de culminar, nos resta indagar un último asunto: a pesar del desplazamiento del orden jurídico y la consecuente preeminencia de la educación para la consecución de la justicia, ¿existe algún campo que amerite un tratamiento legal? $\mathrm{Al}$ respecto, Platón descarta expresamente legislar sobre asuntos que naturalmente parecieran ser materia de ley, tales como: "lances del mercado, de los convenios que en él hacen unos y otros entre sí y (...) los tratos con los artesanos, de las injurias y atropellos, de las citaciones en justicia y las elecciones de los jueces, de la necesidad de tales y cuales exacciones o imposiciones de tributos en plazas y puertos y, en general, de todos los usos placeros, urbanos y marítimos y cuantas cosas hay del mismo estilo" (425c-d). La razón de esta exclusión, a estas alturas, es obvia y se vincula precisamente con el significado mismo de la justicia. De esta forma, si cada cual ha de hacer lo suyo en la polis y, a su vez, cada parte del alma se halla en perfecta armonía, no existiría necesidad de contar con un sistema jurídico que establezca derechos o imponga deberes a hombres justos, capaces de establecer por sí mismos la solución (425d-e). En caso contrario, prosigue, "se pasarían la vida dando y rectificando normas y figurándose que van a alcanzar lo más perfecto" (425e). Pero en un pasaje posterior del Libro IV se formula por última vez la pregunta, parcialmente respondida con anterioridad, acerca del reducido espacio de la ley. Una vez consultado Sócrates sobre qué queda hacer en materia de legislación, este responde brillantemente a su interlocutor: "a nosotros nada [...] [pero] a Apolo, el dios de Delfos, los más grandes, los más hermosos y primeros de todos los estatutos legales" $(427 \mathrm{~b})^{37}$. Una ley como la aludida, sin embargo, obedece a una naturaleza totalmente diferente a aquella de fuente humana y, por lo tanto, tan severa afirmación confirma y transforma en certeza nuestra inicial sospecha: en La República de Platón no existe espacio para la ley ${ }^{38}$.

Entendidas las razones del declarado antagonismo de esta obra hacia la ley, surge un último aspecto a determinar. Y es que contemporáneamente el concepto "ley" tiene una significación precisa como fuente formal del derecho. La ley, se dice actualmente, es solo uno de las diversas fuentes que integran un orden jurídico. Por ende, un examen más acucioso de esta obra nos constriñe a preguntarnos si acaso Platón tuvo en mente esta distinción. Se trata de una interrogante que no

educación. Esta última sería particularmente relevante pues, comprendida su armonía, sería posible aprehender la armonía de la justicia.

${ }^{36}$ JAEGER, Werner, cit. (n. 34), p. 58.

${ }^{37}$ Inmediatamente después son detalladas estas materias, aduciendo que corresponden a "Las erecciones de templos, los sacrificios y los demás cultos de los dioses, de los demones y de los héroes; a su vez, también, las sepulturas de los muertos y cuantas honras hay que tributar para tener aplacados a los del mundo de allá" (427b).

${ }^{38} \mathrm{O}$, para ser más precisos, para la ley h u $\mathrm{m}$ a $\mathrm{n}$ a . 
está exenta de dificultades. Desafortunadamente para nosotros, a pesar de tratarse de un filósofo que discurrió significativamente en torno a cuestiones jurídicas, no contamos con un panorama completo ni explícito que constituya una teoría del derecho de Platón ${ }^{39}$, lo que, sin embargo, no impide que podamos analizar con detención sus aportes para llegar a una respuesta al problema planteado.

Las posibles respuestas a esta interrogante oscilan en dos direcciones: una alternativa es admitir que Platón dirige su crítica exclusivamente a la ley en el sentido estricto ya mencionado; la otra, en cambio, es reconocer que la alusión a la ley es en un sentido más amplio, abarcando en esta noción a todo el orden jurídico y, por consiguiente, asimilándola al derecho. Si bien Platón, como anticipábamos, no proporcionó una respuesta directa, existen dos grandes argumentos para inclinarnos por la segunda opción: uno de naturaleza filosófica y otro de carácter filológico. El primero versa en torno a una de las consecuencias de lo ya esbozado antes: admitir un desprecio parcial de lo jurídico, esto es, solo referido a la ley en sentido restringido, implicaría, a su vez, un triunfo meramente parcial de la educación $(\pi \alpha \iota \delta \varepsilon i ́ \alpha)$ frente al orden legal. Esta situación impediría, en el estado ideal, la consecución de la justicia y, además, contravendría lo expresamente señalado por Platón en múltiples pasajes de la obra en comento. La educación, por tanto, torna irrelevante y superflua no solo a la ley, sino al derecho en su conjunto. El segundo argumento, en cambio, inquiere en torno al significado mismo de la expresión griega vó $\mu$ os, tradicionalmente entendido como ley, pero cuyo sentido genuino estaría dado, más bien, por la noción de r e g l a ${ }^{40} \mathrm{y}$, así entendida, entregaría buenas razones para entender, en La República, derecho y ley de manera indistinta. De esta forma, pues, el triunfo de la educación sobre las reglas jurídicas es avasallador ${ }^{41}$, relegando a las reglas jurídicas a un lugar que no merece siquiera ser llamado secundario.

\section{CONClusiones}

1. Sin lugar a dudas, el Libro IV de La República constituye la sede de las más sistemáticas reflexiones acerca de la justicia. En él no solo se realiza una aproximación general del problema, sino que también se concentran importantes esfuerzos en abordar temáticas directamente vinculadas a aquella, como son la educación y el rol de la ley.

2. El concepto de justicia empleado por Platón se vale de un novedoso método consistente en concebir a la polis como una gran alma o, si se quiere, al alma como una pequeña polis. Esta dualidad es la base de su doble configuración de la justicia: una de carácter social, cuya sede es la polis, y otra de carácter individual, situada en el alma.

39 Woozley, Anthony, Plato and the need for law, en The Philosophical Quarterly 239 (2010), p. 374.

${ }^{40}$ Ibid, p. 383.

${ }^{41}$ Para una lectura alternativa, contra la aversión a la ley en y una defensa al Estado de Derecho en La República, véase Hall, Jerome, Plato's legal philosophy, en Indiana Law Journal 31 (1956), pp. 178-184. 
3. En lo que concierne a la justicia social, esta es concebida por Platón a través de la escisión tripartita de las clases que lo componen: gobernantes, guerreros y obreros. Cada uno de ellos tiene una virtud preponderante y, guiados por el principio de función específica, una polis será justa en la medida en que cada cual haga lo suyo y no se entrometa en lo que por su naturaleza le corresponda a los demás.

4. La justicia individual presupone una idéntica división, esta vez, al interior del alma. De esta forma, es posible identificar tres partes: racional, irascible y concupiscible; cada una de ellas, del mismo modo que la polis, posee sus propias virtudes características. La justicia, en esta sede, consiste en la armoniosa articulación de las tres partes que componen el alma.

5. Sin perjuicio de su preponderante carácter interno, la justicia individual no se agota exclusivamente en la consideración del alma del individuo: esta reclama, además, una manifestación externa que consista precisamente en desplegar aquellas conductas que ratifiquen y consoliden la armonía del alma. La justicia individual, por tanto, no se cimienta en términos puramente ontológicos sino también deontológicos.

6. A pesar de tratarse de dos dimensiones igualmente importantes, y sin restarle méritos a la justicia individual, hemos advertido que la genuina justicia primaria es la social, pues solo la recta conformación de la polis provee un idóneo terreno que permita forjar y, una vez verificada, mantener la justicia en el alma del individuo. Si bien existe mutua dependencia entre justicia social e individual, existe, no obstante, un grado mayor de dependencia de ésta a aquélla, que se erige como su principio arquitectónico.

7. En el escenario ético-político trazado en La República, la ley no ocupa rol alguno: una polis informada por la justicia no requiere orden jurídico que imponga lo ya logrado, y en una polis enferma, la ley carece de eficacia. Atendido ello, la función de formación de la ciudadanía, que en la clásica polis griega era encomendada a la ley, es sustituida ahora por la educación como paradigmática herramienta de generación y corroboración de la justicia.

\section{BiBLIOGRAFÍA}

Alcoberro Pericay, Ramón, Platón. Las respuestas más vigentes a las grandes preguntas sobre el conocimiento, la ética o la justicia (Barcelona, RBA, 2015).

Annas, Julia, An introduction to Plato's Republic (New York, Oxford University Press, 1981).

Bodenheimer, Edgar, Teoría del Derecho (México D.F, Fondo de Cultura Económica, 1994).

CaÑas Quirós, Roberto, La justicia en el alma del flósofo según Platón, en Revista de Filosofia de la Universidad de Costa Rica 81 (1995), pp. 197-204.

Cooper, John M., The psychology ofjustice in Plato, en American Philosophical Quarterly 14 (1977), 2, pp. 151-157.

DAHL, Norman O., Plato's defense of justice, en Philosophy and Phenomenological Research 51 (1991), 4, pp. 809-834.

Foster, M.B., On Plato's conception of justice in the Republic, en The Philosophical Quarterly (1951), 3, pp. 206-217. 
Gómez Robledo, Antonio, Platón. Los seis grandes temas de su filosofía (México D.F, Fondo de Cultura Económica, 1986).

Graneris, Giuseppe, El concepto de justicia en Sócrates, Platón y Aristóteles, en Revista de Derecho Público 17 (2014), pp. 11-23.

GuTHRIE, W.K.C, Historia de la filosofía griega, tomo IV. Platón. El hombre y sus diálogos: primera época (Madrid, Gredos, 1998).

HaLl, Jerome, Plato’s legal philosophy, en Indiana Law Journal 31 (1956), pp. 171-206. JAEGER, Werner, Alabanza de la ley. Los origenes de la filosofía del derecho y los griegos (Madrid, Centro de Estudios Constitucionales, 1982).

Kelsen, Hans, Platonic justice, en Ethics 48 (1938), 3, pp. 367-400.

Kelsen, Hans, ¿Qué es la justicia? (México D.F, Fontamara, 1991).

Moнr, Richard D., The eminence of social justice in Plato, en Illinois Classical Studies 16 (1991), 1-2, pp. 193-199.

Platón, La república (Madrid, Alianza Editorial, 1991).

POPPER, Karl, La sociedad abierta y sus enemigos (Barcelona, Paidós, 2006).

SACHS, David, A Fallacy in Plato's Republic, en The Philosophical Review 72 (1963), 2, pp. 141-158.

Woozley, Anthony, Plato and the need for law, en The Philosophical Quarterly 239 (2010), pp. 373-395. 